\title{
MN20, a D2 Cyclin, Is Transiently Expressed in Selected Neural Populations during Embryogenesis
}

\author{
M. Elizabeth Ross, Michelle L. Carter, and Jang Hern Lee \\ Laboratory of Molecular Neurobiology and Development, Department of Neurology, University of Minnesota, Minneapolis, \\ Minnesota 55455
}

Although the regulation of proliferation and differentiation during brain development has long been considered to be interrelated, the mechanisms that coordinate the control of cell division and histogenesis are poorly understood. The cell cycle is a dynamic process that is governed by the concerted action of numerous cell cycle regulatory proteins in response to signals both intrinsic and extrinsic to the cell. Thus, proteins that regulate the cell cycle are well suited to provide a link between processes that control neuroblast proliferation and differentiation. We reported previously the isolation from brain of a message form of D2 cyclin, one of several cyclin proteins known to promote the progression from $\mathrm{G} 1$ to $\mathrm{S}$ phase. This MN20/D2 cyclin mRNA is expressed in highly restricted neural populations at embryonic (E) day 15 and postnatal $(P)$ day 6 in the mouse. To gain insight into the role(s) this cyclin may serve in brain formation, the spatial and temporal pattern of MN20/D2 cyclin expression was examined by in situ hybridization at $48 \mathrm{hr}$ intervals from E10.5 to P8. MN20 mRNA was detected in developing cerebellum, dorsal mesencephalon, cerebral cortex, and epi- thalamus, but not hippocampus, striatum, or thalamus. Comparison with 5-bromodeoxyuridine labeling of cells in $S$ phase indicated that MN20 expression in embryonic cerebellum and cerebral cortex was most pronounced in young neurons that recently had become postmitotic. Although expressed in other embryonic cerebellar neurons, MN20 was detected in granule precursors only postnatally, after their migration from the rhombic lip to the external germinal layer. This indicates that MN20/D2 cyclin is induced in cerebellar granule precursors as they become competent to differentiate. The spatial distribution of MN20 expression in the developing brain suggests that regional differences in cell cycle regulation depend in part on the selective use of cyclin proteins. Moreover, detection of MN20 mRNA in postmitotic neural cells indicates that cyclin D2 expression has effects beyond promoting cell cycle progression and may also have a role in the response of the neural precursor to terminal differentlation signals as the cell exits from proliferation.

Key words: D2 cyclin; cell cycle regulation; fate determination; granule cell differentiation; cerebellum; cerebral cortex
Throughout vertebrate neurodevelopment, the length of the cell cycle and, hence, cell proliferation, is modulated exquisitely both over time and within specific anatomic regions to affect central nervous system (CNS) histogenesis. A number of observations suggest that these variations in proliferation are related to the stage-specific differentiation of cells within the neuroepithelium. For example, cell cycle times lengthen progressively with increasing cell differentiation in the neuroepithelium over the period of neural tube closure (Kaufman, 1968; Waechter and Jaensch, 1972; Wilson, 1982). Moreover, studies in the early neural tube indicate that the mitotic density and generation time of cells in the basal floor plate and dorsal alar plate vary independently of each other (Hamburger, 1948; Kaufman, 1968). Mitotically synchronous clonal strings of cells have been observed within neuroepithelium that contribute to early regional CNS morphogenesis (Kimmel et al., 1994). At later stages, variation in rates of cortical neurogenesis within the ventricular neuroepithelium contribute to the regional differences in neuronal number in the cerebral cortex

Received July 10, 1995; revised Aug. 28, 1995; accepted Sept. 1, 1995.

This work was supported by National Instilutes of Health Grants NS31318 and NS30627 to M.E.R.

Correspondence should be addressed to Dr. M. Elizabeth Ross, Laboratory of Molccular Neurobiology and Development, Department of Neurology, University of Minnesota, 420 Delaware Street SE, P.O. Box 295, UMHC, Minneapolis, MN 55455.

Dr. Lee's current address: Department of Physiology, College of Veterinary Medicine, Seoul National University, Suwon, Korea.

Copyright (C) 1995 Society for Neuroscience 0270-6474/95/160210-10\$05.00/0
(Dehay et al., 1993). Although the progressive lengthening of the cell cycle within the CNS germinal epithelium coincides with increasing differentiation of neural cells as their fate is determined successively, little is known regarding the molecular mechanisms that coordinate the cellular response to mitogenic and differentiation signals. A likely focal point for the integration of growth and trophic influences is the manipulation of gene expression that regulates the cell cycle.

The cell division cycle is parceled into four distinct phases: mitosis (M), first gap (G1), DNA synthesis (S), and second gap (G2). These phases have been defined by characteristic cytological criteria, incorporation of labeled nucleotides into DNA, cellular DNA content, and protein expression patterns (for review, see Murray and Hunt, 1993; Sherr, 1994; Roberts, 1993). Progression through the cell cycle is driven by the interaction of multiple proteins that must act in concert to regulate the advance through key restriction or check points, notably the G1 to S and G2 to M transitions of the cycle. Known control proteins include the cyclins, which are regulatory subunits of specific cyclin-dependent protein kinase (cdk) partners (Roberts, 1993; Sherr, 1993, 1994). Specific cyclins act to control passage through the cell cycle checkpoints so that cyclins $A, B 1$, and $B 2$ control $G 2 / M$, and the G1 active cyclins, D1, D2, D3, and E, control G1/S. The cyclincdks are modulated in turn by numerous kinases, phosphatases, oncogenes such as p53 and pRb, and cdk inhibitors p16, p21, and p27 (Kato et al., 1994; Matthias and Hershowitz, 1994; Sherr, 
1994). Thus, there is ample opportunity for subtle modulation of the cell cycle in a stage-specific and regional anatomic manner during embryogenesis.

Previous studies have indicated that the lengthening of generation times of ventricular neuroepithelium during vertebrate development is caused largely by the lengthening of $\mathrm{G} 1$ phase (Kaufman, 1968; Waechter and Jaensch, 1972; Wilson, 1982). G1 regulation is important for both the cell's commitment to divide (for review, see Reed et al., 1992; Nasmyth, 1993; Hunter and Pines, 1994; Nurse 1994) and for its ability to respond to extracellular mitogenic and growth signals (Pardee, 1989; Matsushime et al., 1991, 1992; Kato and Sherr, 1993; DeHamer et al., 1994; Thomas et al, 1994). In addition, there is evidence from Drosophila that expression of selected cell cycle genes in $\mathrm{G} 1$ is under developmental rather than cell cycle control (Duronio and O'Farrell, 1994; Edgar et al., 1994). Moreover, in the Drosophila mutant roughex, failure to establish $\mathrm{G} 1$ phase in cells of the developing eye leads to alterations in patterning and fate determination (Thomas et al., 1994). Therefore, the examination of the relationship betwecn cell cyclc gene expression, particularly in G1, and neural differentiation is likely to yield insight into the coordinate control of cell proliferation and fate determination.

We reported previously the isolation of MN20, a message form of the G1-active, D2 cyclin, which is expressed in selected CNS neuronal precursor populations at postnatal day 6 (P6) and embryonic day 15 (E15) (Ross and Risken, 1994). To gain insight into the function of this message form, we have used in situ hybridization to examine the regional distribution and time course of MN20/D2 cyclin expression from E10.5 to P8. MN20 mRNA is expressed in brain in a highly restricted temporal and regional anatomic pattern. MN20 is labeled heavily in populations of young neurons in a transition state between proliferation and acquisition of their mature neuronal phenotype. The data indicate a role for MN20 expression as certain neuroblasts make their final exit from the cell cycle.

\section{MATERIALS AND METHODS}

Establishment of gestational age. Mice were maintained in a $12 \mathrm{hr}$ lightdark cycle. Adult $\mathrm{C} 57 \mathrm{Bl} / 6 \mathrm{~J}$ pairs were placed in mating cages in the evening. Noon of the day on which a vaginal plug was observed was designated E0.5. Once paired, presumed pregnant dams were separated from their mates to ensure accurate determination of gestational age.

In situ hybridization. Techniques for in situ hybridization were similar to those described previously (Ross and Risken, 1994). Tissues from C57Bl/6J mice were fixed in $4 \% p$-formaldehyde in PBS, pH 7.3. P6 animals were anesthetized intraperitoneally with Nembutal and perfused transcardially by gravity, and brains were removed and postfixed in p-formaldehyde for $1-2 \mathrm{hr}$ at $4^{\circ} \mathrm{C}$. Brains of E10.5, E12.5, E14.5, E16.5, and E18.5 animals were removed after anesthetization and killing, used whole or cut in the midsagittal plane, and drop-fixed in $p$-formaldehyde for 2-4 hr. Fixed tissue was then embedded frozen in Tissue-Tek OTC compound (Miles, Elkhart, IN), mounted and sectioned $(10-15 \mu \mathrm{m})$ at $-20^{\circ} \mathrm{C}$ on a microtome, and mounted on polylysine or Vectabond (Vector, Burlingame, CA)-coated slides. Sense and antisense RNA probes corresponding to MN20/cyclin D2 (Ross and Risken, 1994) were transcribed in vitro using the appropriate RNA polymerases (Boehringer Mannheim, Mannheim, Germany), in the presence of $1 \mu \mathrm{M}$ digoxigenin dUTP in a $40 \mu \mathrm{l}$ reaction according to the method described for the Genius system (Boehringer Mannheim). RNA probes were then subjected to partial alkaline hydrolysis to reduce probe size to 200-300 nucleotide fragments. After treatment in $1 \mu \mathrm{g} / \mathrm{ml}$ proteinase $\mathrm{K}$, sections were dehydrated again and hybridized with probe in buffer containing $50 \%$ formamide, $0.3 \mathrm{M} \mathrm{NaCl}, 0.1 \mathrm{M}$ Tris, pH 8, $1 \mathrm{~mm}$ EDTA, $5 \times$ Denhardt's solution, $10 \%$ dextran sulfate, and $100 \mu \mathrm{g} / \mathrm{ml}$ yeast tRNA. Slides were incubated for $16-24 \mathrm{hr}$ at $60^{\circ} \mathrm{C}$. The stringency of the final wash was $0.2 \times \mathrm{SSC}$ at $60^{\circ} \mathrm{C}$ for $1 \mathrm{hr}$. Slides were incubated at $4^{\circ} \mathrm{C}$ overnight, submerged in alkaline-conjugated goat anti-digitoxigenin
$\mathrm{F}\left(\mathrm{ab}^{\prime}\right)_{2}$ antibody (Boerhinger Mannheim) at 1:1000 dilution, before washing and detection of label with NBT and X-phosphate. Slides were photographed using an Optiphot-2 light microscope (Nikon) to produce photographic plates. Drawings were produced from tracings of sections, which were computer-scanned and overdrawn in MacDraw Pro (Claris), and finally transferred to photographic prints for inclusion in the plates.

BrdU labeling and NADPH diaphorase histochemistry. Proliferating cells were identified in E12.5 and E14.5 brains by immunohistochemical detection of incorporated 5-bromodeoxyuridine (BrdU) according to the method of Gratzner (1982). Pregnant dams were injected with $2 \mu \mathrm{l} / \mathrm{gm}$ i.p. of a $10 \mathrm{mg} / \mathrm{ml}$ solution of BrdU in PBS, $2 \mathrm{hr}$ before killing. Tissues were then fixed and sectioned as described above. Alternating sections were processed either for in situ hybridization as above or stained with a 1:100 dilution of rat monoclonal anti-BrdU antibody [Amersham (Arlington Heights, IN) or Sera (Sussex, UK)] and visualized using diaminobenzidine as substrate, according to the manufacturcr's instructions. E14.5 tissues were stained with hematoxylin and eosin (H\&E) using a standard protocol. Nitric oxide producing cells were identified by histochemical stain for NADPH diaphorase (NADPHd) (Bredt et al., 1991; Iadecola et al., 1993). Briefly, slides were incubated at room temperature for $90 \mathrm{~min}$ in buffer containing $1 \mathrm{~mm} \mathrm{NADPH}, 0.2 \mathrm{~mm}$ Nitro Blue Tetrazolium, in $0.1 \mathrm{M}$ Tris- $\mathrm{HCl}$, with $0.2 \%$ Triton $\mathrm{X}-100, \mathrm{pH} 7.4$. No staining was obtained if NADPH was removed from the reaction buffer.

\section{RESULTS}

\section{In situ localization of MN20 expression}

In the embryonic and early postnatal brain, MN20/D2 cyclin is expressed transiently in anatomically restricted populations of differentiating neural cells. The major features of MN20 expression are shown in photomicrographs of Figures $1-4$ and are summarized in their companion diagrams.

At E10.5, the most prominent MN20 expression is detected in the roof of the mesencephalic vesicle (Fig. $1 A, B$ ). MN20 labeling is just discernible at this age in the telencephalic vesicle (Fig. $1 A$ ) but is not seen at E10, suggesting that MN20 expression in the embryonic cerebral wall begins at approximately E10.5. Expression of this cyclin message also is detected in the E10.5 cerebellum, with the heaviest labeling found in cells at the dorsal aspect of the anlage (Fig. 1B). Although MN20 expression is found in some scattered cells of the cerebellar ventricular neuroepithelium at E10.5, it clearly is not confined to the actively proliferating progenitor cell population of the ventricular zone. This pattern suggests that MN20 expression begins when cells are in the ventricular neuroepithelium and increases as they move out toward the dorsal surface of the telencephalon, mesencephalon, and cerebellar rhombencephalon

By E12.5, mesencephalic MN20 expression is restricted posteriorly to the developing tectum (Fig. $2 D$ and diagram, solid arrowhead). In this region of the mesencephalon, MN20 is found predominantly in cells that have migrated out from the proliferative neuroepithelium. Expression is maximal in the dorsal telencephalon at E12.5 (Fig. $2 A, B$ ). At this age, heavy MN20 labeling is seen in postmitotic, densely packed cells in the superficial aspect of the cerebral wall (compare with Fig. 6A). Above the cerebral wall are found cells of the pia-arachnoid, forming skull, and skin, which are retained variably through processing from slide to slide and which do not label for MN20 (Fig. 2). MN20 expression also is seen in the region of the epithalamus (Fig. $2 C$ ), corresponding to the mamillary area (Schambra et al., 1992). In the region of the cerebellar anlage at E12.5, MN20/D2 cyclin is detected transiently largely in cells of the dorsal aspect of the anlage (Fig. 2D). According to the distinction of Altman (1985), these cells correspond to the differentiating zone $(d z)$, which is comprised of recently postmitotic cells giving rise to the deep cerebellar nuclei. Despite its expression in postnatal granule precursors, MN20 labeling is absent in embryonic granule precursors both in the 

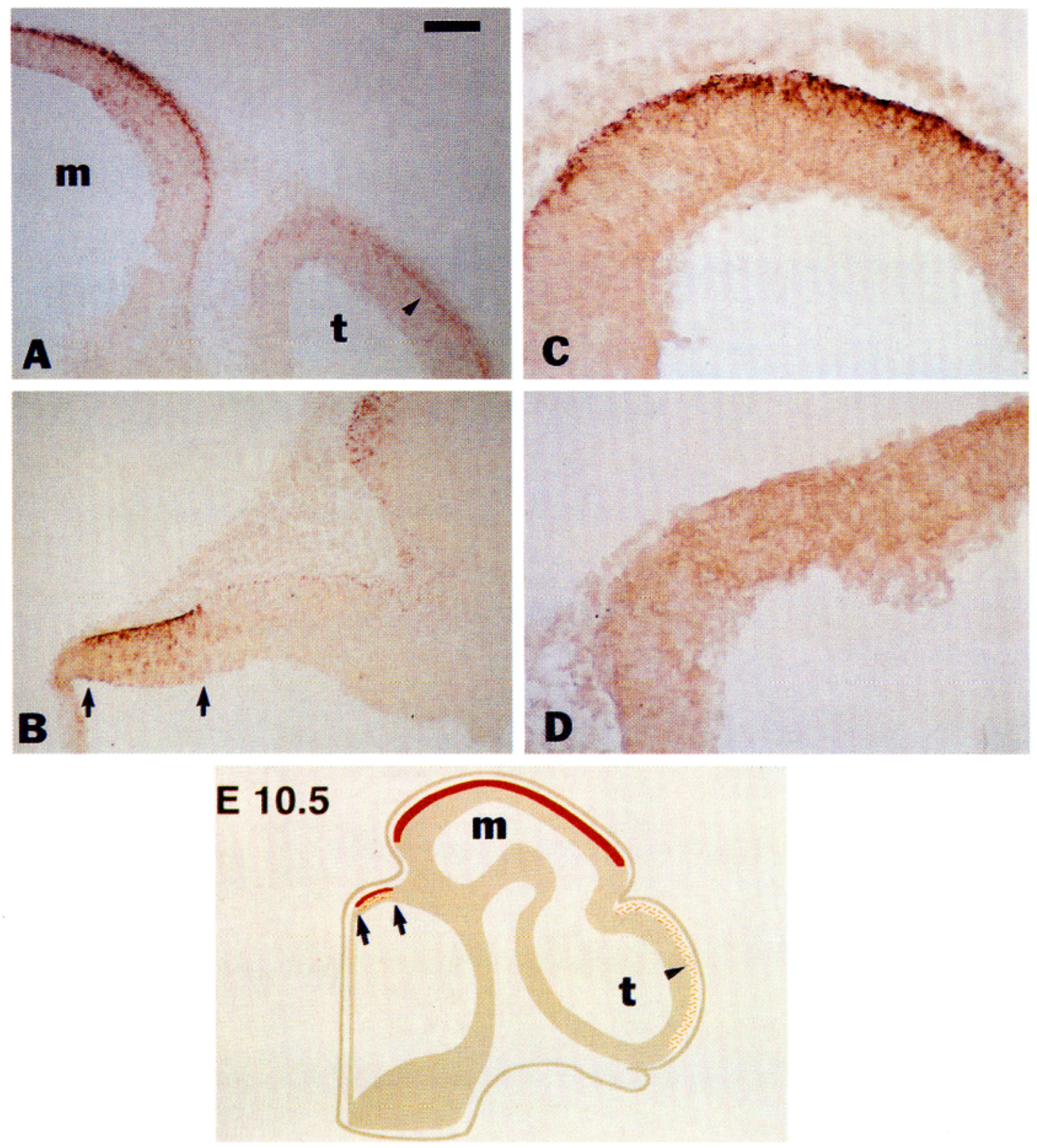

Figure 1. In situ hybridization of MN20 in brain at E10.5. Digoxigenin-labeled antisense riboprobe was transcribed from a fragment at the far $3^{\prime}$ end of the cDNA and hybridized to the endogenous MN20 mRNA in sagittal tissue sections as described in Materials and Methods. MN20 labeling is indicated by a red line or stippling in the summary diagram of an E10.5, midsagittal section. $A$, Heavy MN20 labeling is detected in the dorsal aspect of the mesencephalic vesicle $(m)$, whereas expression is just becoming detectable in the dorsal telencephalic vesicle $(t)$ where the arrowhead points to light MN20 labeling. $B$, In the developing cerebellum, demarcated by the two arrows, MN20 message is expressed most heavily in the dorsal aspect of the anlage, Scattered cells of the cerebellar ventricular neuroepithelium are also labeled. $C$, MN20 expression in the roof of the mesencephalic vesicle is shown at higher magnification. The MN20/D2 cyclin mRNA is detected primarily in cells at the outer aspect of the proliferative neuroepithelium. $D$, As a negative control, adjacent sections were hybridized with sense strand MN20 riboprobe. Shown in $D$ is the mesencephalic region comparable to that which appears in $C$. Scale bars: $400 \mu \mathrm{m}$ in $A$ and $B$ and $100 \mu \mathrm{m}$ in $C$ and $D$.

rhombic lip at E12.5 and E14.5 and those migrating to the cerebellar EGL. This indicates that embryonic cerebellar granule precursors do not express MN20/D2 cyclin even though they are mitotically active (see Fig. 6).

At E14.5, virtually no MN20 expression is found in the cerebellar anlage, and it does not reappear until the early postnatal period when it is found in the P2 EGL, the earliest postnatal age examined. However, strong MN20 labeling is found in a thin layer of cells lining the most superficial aspect of the nascent cortical plate (Figs. 3, 5). MN20 expression in this region extends antero- posteriorly from frontal to occipital cortex and excludes the olfactory cortex. These MN20 expressing cells are not glial precursors because the few glia that arise from the ventricular zone at this age remain scattered in the region of the subventricular and ventricular zones, below the cortical plate, until later in development (Angevine and Sidman, 1961; Bayer and Altman, 1991). Little if any labeling is detected either in cells migrating through the intermediate zone toward the cortical plate or in cells of the underlying ventricular zone. MN20 expression is not detected in the developing hippocampus at E14.5. In situ labeling with MN20 
sharply declines in the cerebral cortex by E16.5 and is undetectable in the early postnatal period.

In the P6 mouse brain, MN20 expression is confined to the superficial lamina of the external germinal layer (Fig. 4B), where $\left[{ }^{3} \mathrm{H}\right]$ thymidine labeling studies have indicated that granule neuron precursor cells are mitotically active (Fujita, 1967). No labeling is detected in the deep lamina of the EGL, where cells become postmitotic, begin to extend processes, and form attachments to radial processes of Bergmann glia in preparation for granule cell descent into the IGL (Ramon y Cajal, 1911; Miale and Sidman, 1961; Fujita, 1967; Rakic, 1971; Altman and Bayer, 1985; Ryder and Cepko, 1994). At this age, no MN20 expression is detected elsewhere in the brain, including the postnatal cerebral cortex (Fig. $4 C$ ). Moreover, there is no MN20 expression detected in the P6 hippocampus, which still contains dividing granule neuron precursors in the postnatal period (Fig. 4D). The MN20 expression pattern observed at $\mathrm{P} 6$ is identical to that seen at P2, P4, and $\mathrm{P} 8$.

\section{MN20 also is expressed in postmitotic, immature neurons during embryogenesis}

Comparing adjacent tissue sections (Fig. 5), MN20 expression is seen to overlap with that of the neuronal NOS/NADPHd-expressing cells recently observed in developing neocortex (Bredt and Snyder, 1994). These NOS cells represent postmitotic, immature neurons of the developing cerebral cortex. Although NOS-labeled cells form a thin layer at the superficial aspect of the E12.5 cerebral wall, by E14.5 NOS expression extends into the thickness of the emerging cortical plate. This suggests that MN20 is more transiently expressed than NOS in these cells, because it does not persist as cells are displaced to a deeper position in the cortical plate by newly arriving neurons.

A majority of cells in the E14.5 cortex that express high levels of MN20 are postmitotic, as demonstrated by the lack of BrdU incorporation into $S$ phase nuclei (compare Figs. 3 and 5 with Fig. 6). These cells at the top of the cerebral cortical plate are in a transition between exit from the cell cycle and assumption of their more mature neuronal phenotype. These young neurons are located at the interface between the cortical plate and marginal zone (see Fig. 5), and therefore correspond to cells that have just completed their migration from the ventricular zone to the cortical plate and/or to the Cajal-Retzius neurons generated locally in layer I. Similarly, in the E12.5 cerebellar anlage, although there is light labeling in cells of the proliferating neuroepithelium, the heaviest concentration of MN20-labeled cells is seen in the differentiating zone, shown in Figure $2 D$. These cells, originating in the ventricular zone, recently have become postmitotic (compare Fig. $2 D$ with Fig. $6 B$ ) and are thought to give rise to the deep cerebellar nuclei (Altman and Bayer, 1985). MN20 does not appear to be expressed in high levels in the Purkinje cells that emerge from the ventricular germinal epithelium over the period from E10 to E13 in mouse (Miale and Sidman, 1961), because at these ages immature Purkinje cells are found deep in the differentiating zone (Altman and Bayer, 1985). The cells of the differentiating zone will later migrate inward, passing the Purkinje cells, to assume their final position deep in the cerebellum.

\section{DISCUSSION}

Early concepts of the vertebrate neuroepithelium held that this is a simple epithelium of undifferentiated or "indifferent" cells in continuous proliferation (Schaper, 1897; Weiss, 1955). However, a large body of subsequent work indicates that the CNS germinal matrix is a progressively specialized epithelium that changes character over time. During the interkinetic nuclear migration of ventricular cells in the neural tube, bipolar cells in $\mathrm{G} 2$ round up, displacing the nucleus to the ventricular surface for mitosis (Sauer, 1935; Sauer and Chittenden, 1959; Fujita, 1963; Seymour and Berry, 1975). Berry described two broad stages in the development of the ventricular zone: a "proliferative" stage in which the germinal cells divide rapidly and are morphologically identical-although not necessarily equipotential; and a "migratory" stage that appears after cellular differentiation begins (Berry, 1974). In the cerebral cortex, the ventricular zone of the early migratory stage gives rise primarily to neurons, whereas the germinal epithelium turns to gliogenesis in the late migratory stage (Berry, 1974; Bayer and Altman, 1991). As these alterations within the ventricular zone occur, the length of the cell cycle increases. Thus, mechanisms that produce this progressive differentiation of the neuroepithelium must modulate the generation time of the cell in parallel. Insight has been gained recently into the compendium of regulatory proteins that interact to finely control cell cycle progression (for review, see Murray and Hunt, 1993; Sherr, 1994; Roberts, 1993). These regulatory proteins, particularly the G1 cyclins and their cdk partners, may provide an opportunity to coordinate the control of cell proliferation and differentiation in developing brain.

We reported previously the isolation from cerebellar granule cells of a cDNA, MN20, which encodes D2 cyclin protein in an alternatively processed form of the cyclin message (Ross and Risken, 1994), MN20 differs from the more broadly expressed D2 cyclin message in its far $3^{\prime}$-untranslated region (UTR). In the present study, we have examined the temporal and spatial distribution of MN20/D2 cyclin expression during development of the CNS. MN20 is localized transiently in restricted neuronal precursor populations of the embryonic brain. This anatomically restricted pattern of expression indicates that MN20/D2 cyclin is not simply a marker of all proliferating cells in developing brain. Based on these results, we propose that particular neuroblasts, restricted in their differentiation path, may select which cell cycle components to express, thereby determining the length of each phase or whether the cell will stop dividing, either reversibly or irreversibly. This is supported by the observation during Drosophila embryogenesis of mitotic domains, in which clusters of synchronously dividing cells display morphological and gene expression characteristics indicative of early fate commitment (Hartenstein and Campos-Ortega, 1985; Foe, 1989). Similarly in zebrafish, mitotic domains have been ohserved within the neural tube and are thought to reflect cell cycle-dependent morphogenesis of the region, although not necessarily commitment of cells to a particular fate (Kane et al., 1992; Kimmel et al., 1994).

The anatomically restricted distribution of MN20/D2 cyclin expression suggests that it serves a cell-type-specific role in differentiation. This is consistent with the observation that, unlike the more ubiquitously expressed D1 isoform, D2 cyclin is expressed only in selected continuous cell lines (Inaba et al., 1992). In addition, it has been shown that overexpression of the G1 active cyclins D2 or D3, but not D1, can prevent growth factorinduced differentiation of granulocytes in culture (Kato and Sherr, 1993). This inhibitory effect on granulocyte differentiation is absent when mutant D2 cyclin protein lacking a functional retinoblastoma (Rb)-binding sitc is uscd (Kato and Shcrr, 1993). Thus, there is precedent in other systems for both the selective expression of D2 cyclin and its involvement in the maturation of cellular phenotype. 


\section{MN20 expression in developing telencephalon}

The pattern of MN20 expression in cerebral cortex is consistent with a role during neurodifferentiation. Although no labeling was detected in telencephalon at E10, MN20 probe was scen to lightly label cells in the telencephalic vesicle at E10.5. This corresponds to the initiation of the neurogenic epoch, which begins at about E11 in the mouse (Angevine and Sidman, 1961). At E10.5 and E12.5, there is weak MN20 labeling throughout the ventricular neuroepithelium with a progressive concentration of cells at the superficial aspect of the cerebral wall, where the postmitotic cells of the primordial plexiform layer (PPL) reside. The PPL will give rise to layer I and cortical subplate, between which the cortical plate will form and expand (Marin-Padilla, 1971, 1988; reviewed in O'Leary and Koester, 1993). By E14.5, MN20 expression is found transiently at the superficial aspect of the cortical plate. However, it does not appear to persist in the cortical subplate, further indicating that neuronal subpopulations selectively express MN20. 'The present study indicates that these E14.5 cells correspond to largely postmitotic, immature neurons. The number and morphology of cells expressing MN20 suggest that they are newly arrived young neurons from the ventricular zone that express neuronal NOS (Bredt and Snyder, 1994), although it is possible that Cajal-Retzius neurons of layer I also are included. Overlap between NOS expression and MN20 was seen in other brain regions as well, such as the tectum at E12.5. Finally, the attenuation of MN20 labeling in the cortical plate by E16.5 suggests that D2 cyclin action is not uniform throughout cerebral cortical histogenesis, but is most active during the emergence of layer V and VI neurons.

\section{MN20 expression in developing cerebellum}

Within the developing cerebellum, MN20/D2 cyclin is expressed in a bimodal fashion, initially seen at E10.5-12.5 and not again until the postnatal period. Moreover, it is expressed in cells that are making a transition between proliferation and their final exit from the cell cycle. MN20 is detected in the cerebellar anlage at E10.5-E12.5 in cells that will contribute to the deep cerebellar nuclei. At this age, labeled cells are scattered through the cerebellar ventricular neuroepithelium, and more densely labeled cells are seen in the dorsal anlage. This graded expression indicates that the MN20 isoform is expressed first in cells within the ventricular zone and is upregulated as cells become postmitotic, move dorsally, and begin to differentiate (Altman and Bayer, 1985). From E14.5 to E18.5, it is notably absent within the cerebellum and dividing granule precursors of the rhombic lip, which heavily express MN20 only once in the postnatal EGL. This postnatal granule population already has migrated out from the rhombic lip and is undergoing its second and final burst of mitosis as cells prepare to extend processes and begin their inward migration. Thus, these granule precursors are "primed" for terminal differentiation and therefore are comparable, at least in this respect, with the cerebral cortical cells expressing MN20. This suggests that the expression of $\mathrm{MN} 20$ is more dependent on the stage of differentiation of the precursor cell than on the cell's active participation in the division cycle. The pattern of MN20 expression is compatible with a model of neurodifferentiation in which multipotential precursors become committed to a neuronal lineage, then undergo sequential restriction of possible fates that they can assume only after appropriate gene expression renders them competent to differentiate. In such a model, MN20 would be a marker for this intermediate stage in which granule cells acquire competence to differentiate.

\section{Relationship between MN20/D2 cyclin expression and brain development}

What then are the potential roles of MN20/D2 cyclin in the regional differentiation of CNS progenitor cells? Cyclin D2 is known to be a positive regulatory subunit of cdk2 and cdk4 (Xiong et al., 1992; Kato et al., 1993). It has been shown to interact directly with the oncogene product $\mathrm{pRb}$, and the D-cdk complex is inhibited by the cdk inhibitors $\mathrm{p} 21^{\text {cip/waf } 1}$ and p $27^{\text {kip }}$ (Kato et al., 1993; Xiong et al., 1993). During G1 of the cell cycle, D2 cyclin protein is expressed before cyclin $E$ and is a prime target for growth factors that must be administered early in G1 to influence proliferation (Matsushime et al., 1991; Sherr, 1993). The downstream targets of D2 cyclin/kinase partners are little understood, so it is possible that D2 cyclin has a role in differentiation beyond its known role in cell cycle regulation. However, the fact that it is expressed both in cell populations undergoing their final wave of mitosis and also transiently in cells that have just exited the cell cycle strongly implies that MN20/D2 cyclin has a role in the downregulation of proliferation and/or early events in maturation of the young postmitotic neuron.

The influence of $\mathrm{MN} 20 / \mathrm{D} 2$ cyclin on neuronal differentiation could be a permissive one, altering the rate of cell division in precursor cells, thereby modulating the opportunity for gene expression as cells progressively differentiate. One model of gene regulation in Drosophila occurs during early embryogenesis, in which the rapid rate at which cells divide excludes the expression of large genes because there is insufficient time to transcribe and process units on the order of $20 \mathrm{~kb}$ (Shermoen and O'Farrell, 1991; Rothe et al., 1992). Thus, the timing of expression of large genes (transcription units) such as knirps-related and Ultrabithorax is restricted by the stage-specific length of cell cycle times in the

Figure 2. In situ hybridization of MN20 in brain at E12.5. Sagittal sections are labeled with MN20 riboprobe as in Figure 1. Red lines or stippling in the diagram of an E12.5 embryo, depicted in the midsagittal plane, summarize the distribution of MN20 labeling. $A$ and $B$, Low- and high-power magnifications are shown of the cerebral cortical wall. MN20 mRNA is labeled heavily in young postmitotic neurons in the primordial plexiform layer ( $p p l$ ) above the ventricular neuroepithelium (see Fig. $6 A$ ); $l v$, lateral ventricle. $C$, MN20 expression is seen in the mamillary area of the epithalamus. The open arrow in $C$ corresponds to that shown in the diagram. $D$, By E12.5, mesencephalic MN20 expression is restricted posteriorly to the developing tectum (closed arrowhead in $D$ and diagram). In the tectum, MN20 is found predominantly in cells that have migrated out from the proliferating ventricular neuroepithelium. Long arrows point to the cerebellum where MN20 mRNA is detected primarily in cells of the dorsal, differentiating zone ( $d z$ ). The dz is populated by recently postmitotic cells that have migrated up from the ventricular zone $(v z)$ to contribute to the deep cerebellar nuclei (Altman and Bayer, 1985). Suale bars: $200 \mu \mathrm{m}$ in $A$ and $D$ and $100 \mu \mathrm{m}$ in $B$ and $C$.

Figure 3. In situ hybridization of MN20 in E14.5 brain. Sagittal sections are labeled with MN20 riboprobe as in Figure 1. The distribution of MN20 expression in E14.5 brain is represented in the E14.5 diagram by a red line. $A$ and $B$, Lower and higher magnifications of the cerebral cortex. MN20 is expressed in a thin layer of cells (arrows) at the outermost cortical plate $(c p)$, which contains primarily postmitotic neurons at this age. No MN20 labeling is detectable in the ventricular zone $(v z)$, where the proliferating neuroepithelium is located; $l v$, lateral ventricle. MN20 expression extends anteroposteriorly from frontal to occipital cortex and excludes olfactory cortex or hippocampus. $C$, No MN20 expression is seen in the cerebellum at this age (seen in $C$ and designated by an arrow in the summary diagram). Scale bars: $200 \mu \mathrm{m}$ in $A$ and $100 \mu \mathrm{m}$ in $B$ and $C$. 

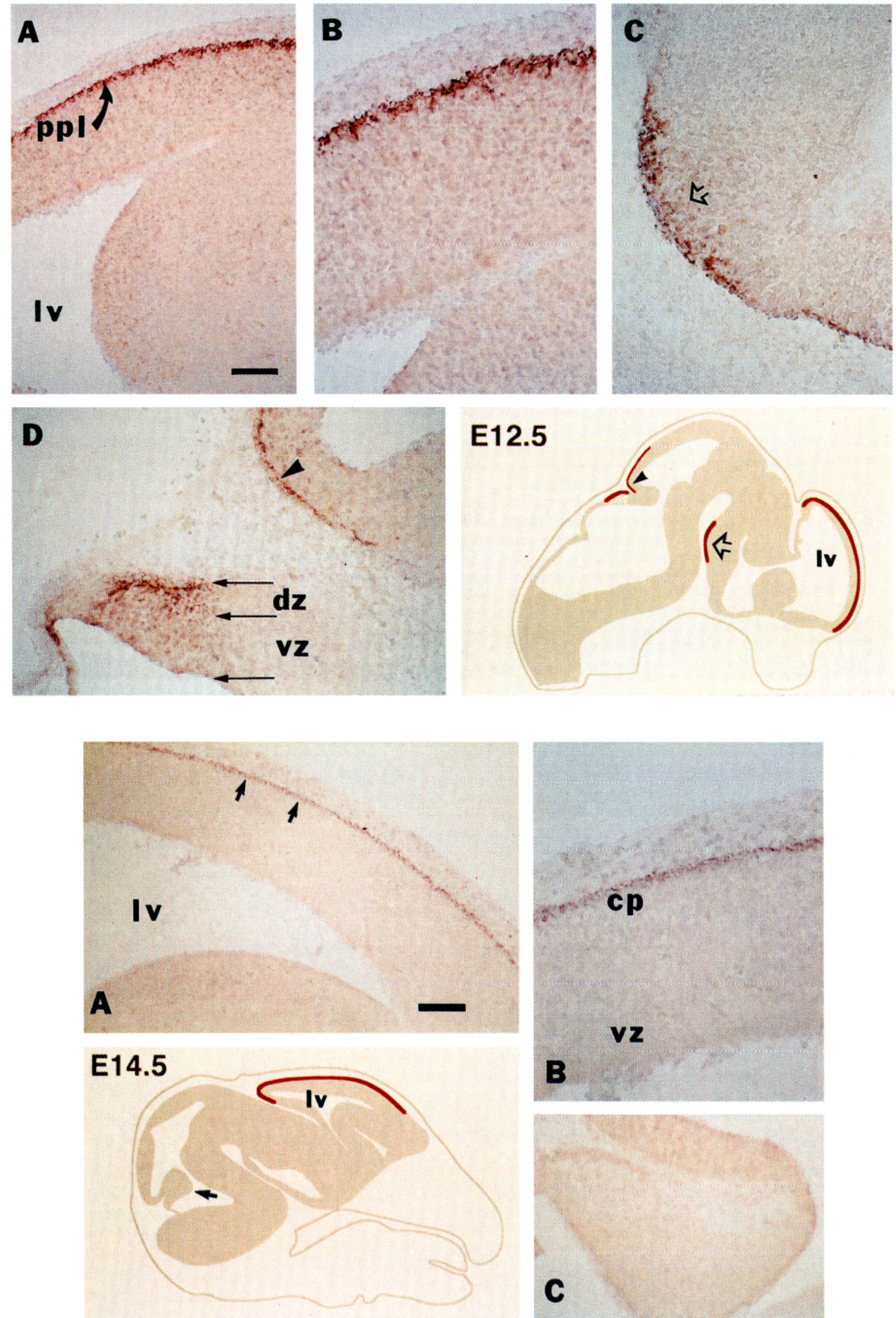

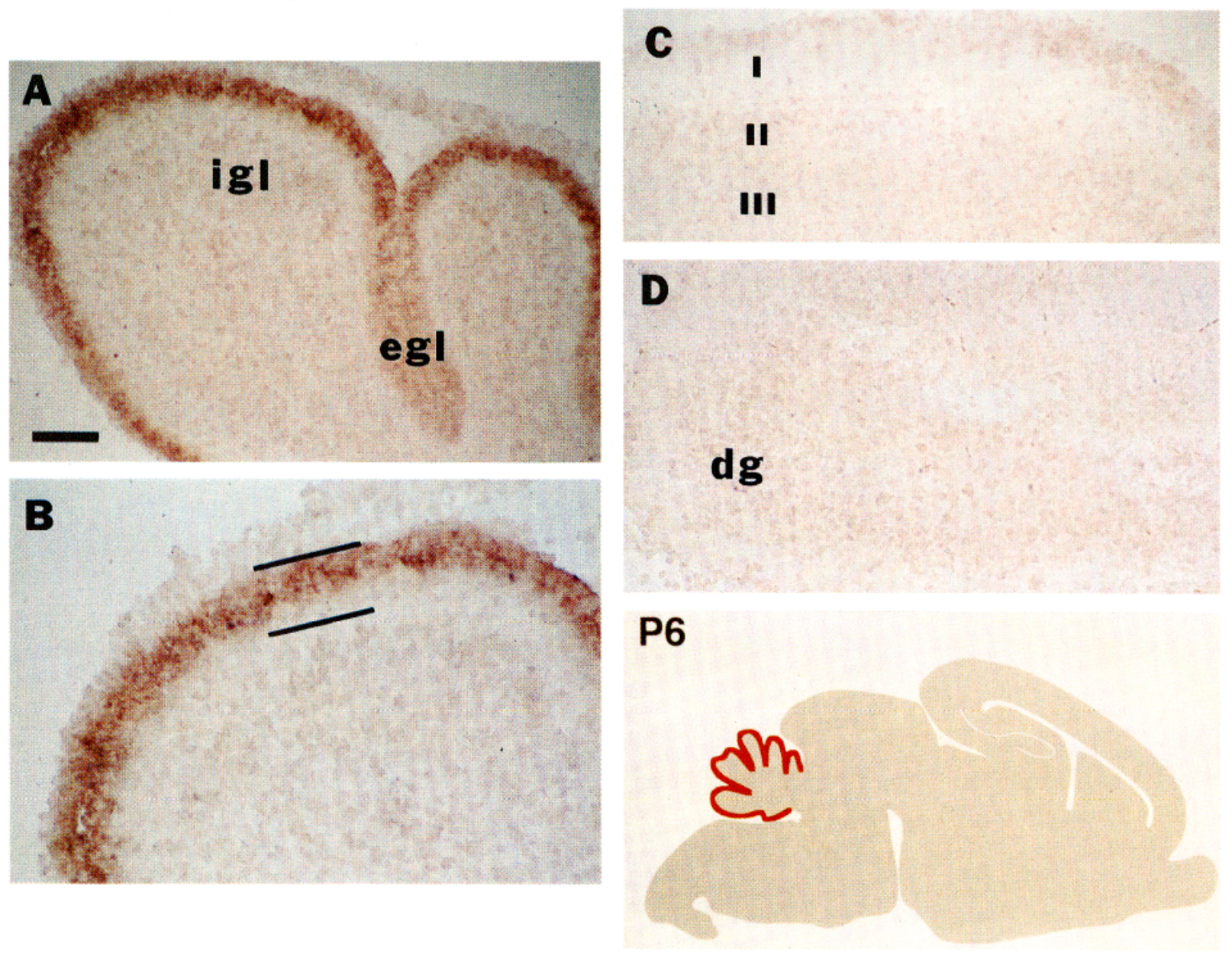

\section{E12.5}

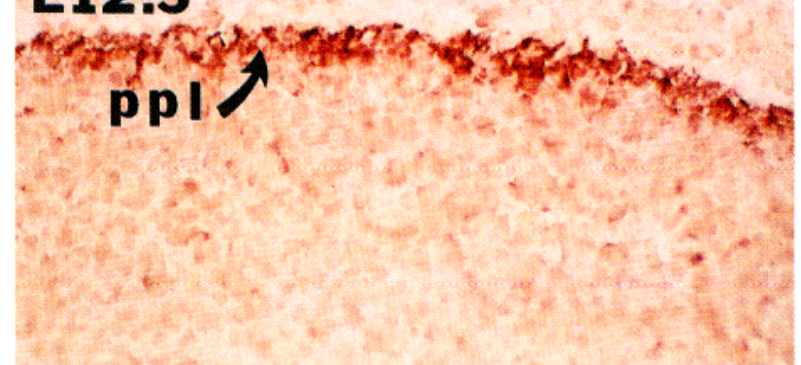

\section{MN20}
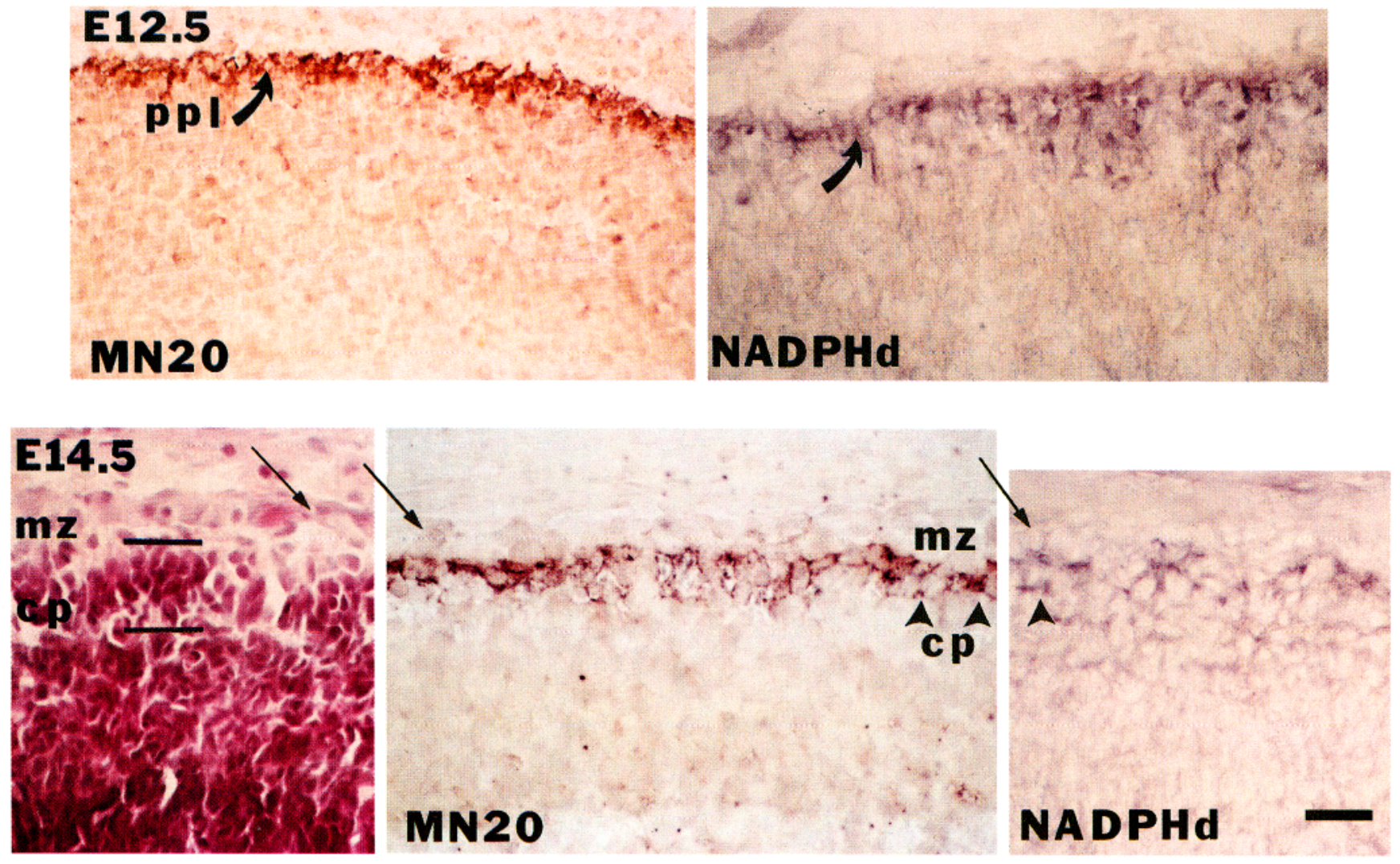


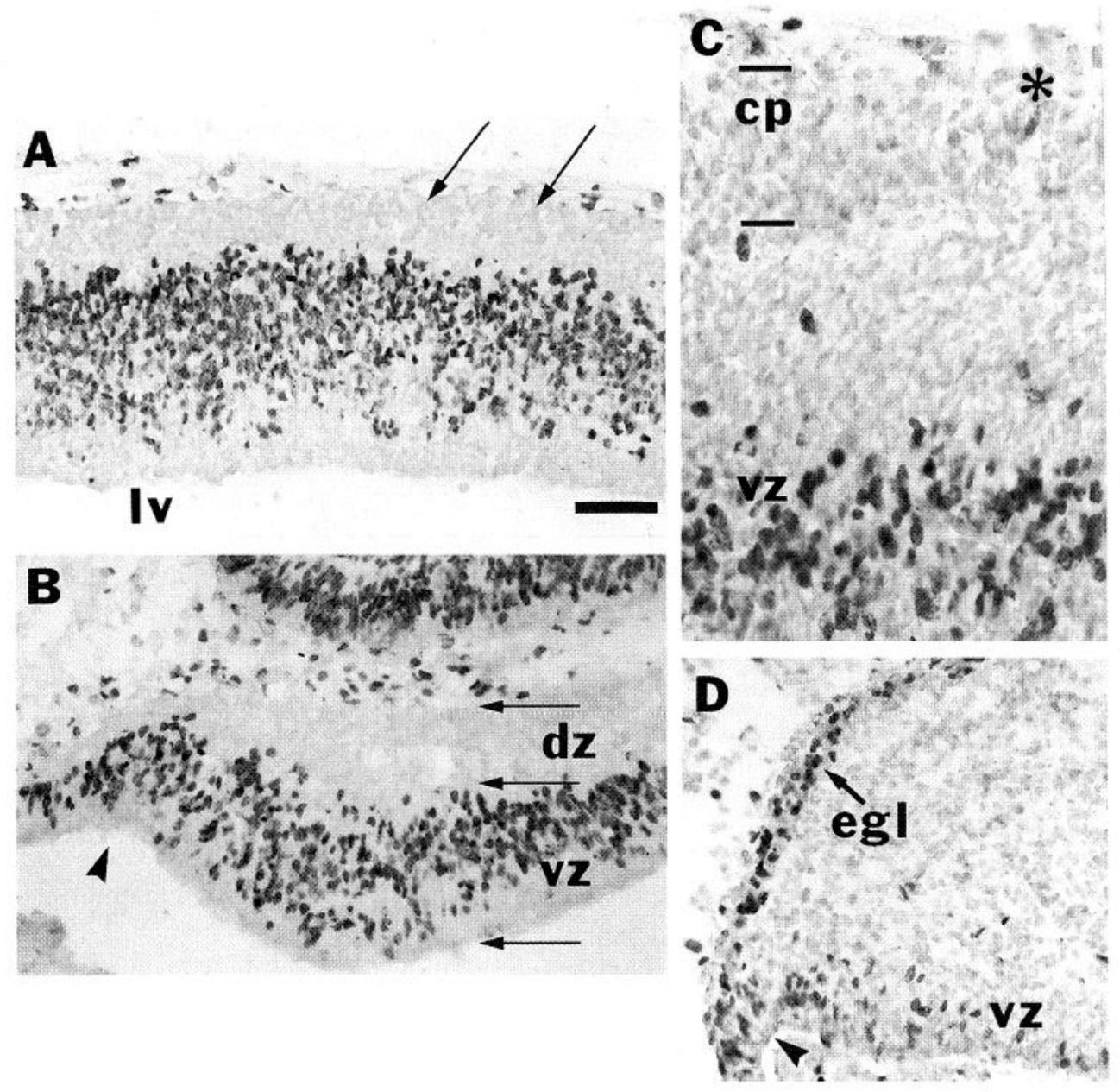

Figure 6. BrdU labeling of proliferating neuroblasts in embryonic cerebral cortex and cerebellum. BrdU incorporation into S-phase nuclei is detected immunohistochemically in sagittal sections of brain at $\mathrm{E} 12.5(A, B)$ and E14.5 $(C, D) . A, \mathrm{E} 12.5$ cerebral cortical wall. Cells of the ventricular zone are labeled heavily, whereas postmitotic cells begin to fill the subpial region and form the primordial plexiform layer. Arrows point to the location of MN20/D2 cyclin-expressing cells shown in Figure $2 A$, $B ; l v$, lateral ventricle. $B$, Arrows point to the E12.5 cerebellar anlage, where proliferating cells are found in the ventricular zone $(v z)$, whereas cells in the differentiating zone $(d z)$ are postmitotic. Compared with Figure $2 D$, the strongest MN20 expression is found in the postmitotic cells of the $\mathrm{dz}$, whereas lower but detectable expression is found in the vz. Cells of the rhombic lip (arrowhead in $B$ and $D$ ) do not express MN20 (compare with Figs. 2, 3). $C$, E14.5 cerebral cortex. BrdU-labeled cells are found predominantly in the ventricular neuroepithelium $(v z)$, although occasional mitotic cells are labeled in the marginal zone above the cortical plate ( $c p$, parallel lines), as are a few cells migrating toward the cp. The asterisk in $C$ designates the level at which MN20-expressing cells are located in Figures 3 and 5. D, BrdU-labeled, S-phase cells of the E14.5 cerebellar anlage are located in the $\mathrm{vz}$ and external germinal layer $(\mathrm{egl})$, the cells of which have migrated out from the rhombic lip (arrowhead). No MN20 message was detected in the E14.5 cerebellum (compare with Fig. 3). Scale bars: $100 \mu \mathrm{m}$ in $A, B$, and $D$, and $200 \mu \mathrm{m}$ in $C$.

developing embryo. This may explain in part the requirement for progressive lengthening of the cell cycle as neurulation and cortical neurogenesis proceed (Kaufman, 1968; Wilson, 1982; Takahashi et al., 1993).

Alternatively, the selection of cell cycle proteins expressed within a given CNS progenitor may be a consequence of the degree to which the fate of that precursor cell is determined. In support of this view, expression of certain cell cycle genes, such as the G1-active cyclin E, proliferating cell nuclear antigen, ribonucleotide reductase, and DNA polymerase- $\alpha$, are expressed in Drosophila regardless of whether there is a block in the cell cycle at G2/M (Duronio and O'Farrell, 1994; Edgar et al., 1994). This indicates that expression of certain components of the cell cycle machinery are under developmental rather than cell cycle control.
The detection of MN20/D2 cyclin mRNA in postmitotic cells could indicate a relationship between "inappropriate expression" of a cell cycle regulatory gene and programmed cell death. Recent work regarding gene expression in an in vitro model of apoptosis on the withdrawal of nerve growth factor suggests that in superior cervical ganglion D1, but not D2, cyclin is a marker of programmed cell death, perhaps by pushing cells through G1 without entering G2 (Freeman et al., 1994). This raises the possibility that in other postmitotic neurons, another $\mathrm{D}$ cyclin has a similar association with apoptosis. Examination of H\&E-stained sections suggests that this mechanism is not a major function of the D2 cyclin in early cortical development, because only very rare pyknotic nuclei, characteristic of cells undergoing apoptotic cell death, were seen in the region of the E14.5 cortical plate. Within the same tissue section, the mesence-

Figure 4. In situ hybridization of MN20 in P6 brain. Sagittal sections are labeled with MN20 riboprobe as in Figure 1. The distribution of expression is indicated by a red line in the diagram of a P6, sagittal brain section. $A$ and $B$, Lower and higher magnifications of the cerebellum are shown. The full thickness of the external germinal layer $(\mathrm{egl})$ is indicated by parallel lines in $B$. Heavy labeling of MN20 is seen in the superficial zone of the egl in which proliferating granule neuron precursors are found. Labeling is absent in the deep zone of the egl, where postmitotic granule cells begin their glia-guided migration inward to the internal granular layer $(\mathrm{igl})$. $C$, The cerebral cortex is devoid of MN20 expression by P6 (cortical layers I and II/III are indicated). $D$, No MN20 labeling is seen in the proliferating granule cells of the hippocampal dentate gyrus $(d g)$. Scale bars: $200 \mu \mathrm{m}$ in $A$ and $100 \mu \mathrm{m}$ in $B-D$.

Figure 5. MN20- and nitric oxide synthase (NOS)-expressing cells in cerebral cortex at E12.5 and E14.5. Comparison of adjacent tissue sections reveals overlap of MN20 expression with NADPH-diaphorase (NADPHd)-labeled, NOS-expressing, cerebral cortical cells. These neuronal NOS cells represent postmitotic, immature neurons of the emerging cerebral cortex (Bredt and Snyder, 1994). E12.5, MN20 expressing cells at the superficial aspect of the cerebral wall are in the region of the primordial plexiform layer ( $\mathrm{ppl}$, curved arrow) and overlap with NOS-producing young neurons, which are just beginning to move out from the ventricular zone. E14.5, An H\&E-stained section is shown at the left in the bottom panel, where parallel lines demarcate the cortical plate $(c p)$. The arrowheads point to MN20- and NADPHd-positive cells at the superficial aspect of the cortical plate $(c p)$, and the long thin arrows point to the overlying marginal zone $(m z)$ and pia. Scale bar, $40 \mu \mathrm{m}$ in both panels. 
phalic nucleus of $\mathrm{V}$ demonstrated readily apparent karyorhexis, indicative of the apoptosis that is known to occur in brainstem nuclei at this age. The cellular morphology of the E14.5 cerebral cortex is not compatible with a model in which MN20 expression marks apoptosis, because the message was found in many more cells than appear to be undergoing programmed cell death. Moreover, the observation of NOS expression in cell populations producing MN20 suggests that these cells are not undergoing apoptosis, because it has been reported that NOS activity can provide protection from programmed cell death (Mannick et al., 1994). Interestingly, it also has been implied that induction of NOS expression in differentiating neural cells are required for their exit from the cell cycle (Peunova and Enlkolopov, 1995), precisely the stage in which MN20 expression is seen to overlap with NOS in cerebral cortex.

The expression of MN20/D2 cyclin mRNA in cells that recently have exited the cell cycle suggests that this message form in some way prevents the further division of cells or otherwise provides a link between incoming trophic signals and the cell cycle. It has been demonstrated in fibroblast cultures that overexpression of D1 or E cyclins can shorten Gl and accelerate proliferation (Ohtsubo and Roberts, 1993; Quelle et al., 1993). Interestingly, it has been observed that a truncation in the $3^{\prime}$-UTR of the D1 cyclin gene has led to stabilization of the mRNA and elevated D1 cyclin protein expression in a human breast cancer cell line (Lebwohl et al., 1994). This suggests that sequences in the $3^{\prime}$-UTR can play a significant role in the regulation of cyclin expression. This is particularly relevant for MN20 because this message form, comprised of $5 \mathrm{~kb}$ of $3^{\prime}$-UTR compared with a coding region of $<1 \mathrm{~kb}$, is distinguished in its $3^{\prime}$ end from the other D2 cyclin message (Ross and Risken, 1994). Moreover, excessive expression of D2 or D3, but not D1, cyclin can prevent granulocyte differentiation in the presence of the growth factor CSF-1 in a lineage-dependent manner (Kato and Sherr, 1993). It is possible, then, that the MN20 form of the D2 cyclin mRNA serves to reduce the translational activity of the D2 cyclin message in neuroblasts to facilitate their exit from the cell cycle and response to terminal differentiation signals.

\section{REFERENCES}

Altman J, Bayer S (1985) Prenatal development of the cerebellar system in the rat: cytogenesis and histogenesis of the deep nuclei and the cortex of the cerebellum. J Comp Neurol 179:23-48.

Angevine JB, Sidman RL (1961) Autoradiographic study of the cell migration during histogenesis of cerebral cortex in the mouse. Nature 192:766-768.

Bayer SA, Altman J (1991) Neocortical development. New York: Raven. Bayer SA, Altman J (1990) Development of layer I and subplate in the rat neocortex. Exp Neurol 107:48-62.

Berry M (1974) Development of the cerebral neocortex of the rat. In: Aspects of neurogenesis (Gottleib G, ed), pp 7-67. New York: Academic.

Bredt DS, Snyder S (1994) Transient nitric oxide synthase neurons in embryonic cerebral cortical plate, sensory ganglia, and olfactory epithelium. Neuron 13:301-313.

Bredt DS, Glatt CE, Hwang PM, Fotuhi M, Dawson TM, Snyder SH (1991) Nitric oxide synthase protein and mRNA are discretely localized in neuronal populations of the mammalian CNS together with NADPH diaphorase. Neuron 7:615-624.

DeHamer MK, Guevara JL, Hannon K, Olwin BB, Calof AL (1994) Genesis of olfactory receptor neurons in vitro: regulation of progenitor cell divisions by fibroblast growth factors. Neuron 13:1083-1097.

Dehay C, Giroud P, Berland M, Smart I, Kennedy H (1993) Modulation of the cell cycle contributes to the parcellation of the primate visual cortex. Nature 366:464-466.

Duronio RJ, O'Farrell PH (1994) Developmental control of a G1-S transcriptional program in Drosophila. Development 120:1503-1515.
Edgar BA, Lehman DA, O'Farrell PH (1994) Transcriptional regulation of string ( $c d c 25)$ : a link between developmental programming and the cell cycle. Development 120:3131-3143.

Foe VE (1989) Mitotic domains reveal early commitment of cells in Drosophila embryos. Development 107:1-22.

Freeman RS, Estus S, Johnson EM Jr (1994) Analysis of cell cyclerelated gene expression in postmitotic neurons: selective induction of cyclin D1 during programmed cell death. Neuron 12:343-355.

Fujita $S$ (1963) The matrix cell and cytogenesis in developing central nervous system. J Comp Neurol 120:37-42.

Fujita S (1967) Quantitative analysis of cell proliferation and differentiation in the cortex of the postnatal mouse cerebellum. J Cell Biol 32:277-287.

Gratzner H (1982) Monoclonal antibody to 5-bromo and 5-iododeoxyuridine: a new reagent for detection of DNA replication. Science 218:474-475.

Hamburger V (1948) The mitotic patterns in the spinal cord of the chick embryo and their relation to histogenetic processes. J Comp Neurol $88: 221-283$

Hartenstein V, Campos-Ortega JA (1985) Fate mapping in wild-type Drosophila melanogaster. I. The spatio-temporal pattern of embryonic cell division. Roux's Arch Dev Biol 194:181-195.

Hunter T, Pines J (1994) Cyclins and cancer II: cyclin D and CDK inhibitors come of age. Cell 79:573-582.

Iadecola C, Faris PL, Hartman BK, Xu X (1993) Localization of NADPH diaphorase in neurons of the rostral ventral medulla: possible role of nitric oxide in central autonomic regulation and oxygen chemoreception. Brain Res 603:173-179.

Inaba T, Matsushime H, Valentine M, Roussel MF, Sherr CJ, Look AT (1992) Genomic organization, chromosomal localization, and independent expression of human cyclin D genes. Genomics 13:565-74.

Kane DA, Warga RM, Kimmel CB (1992) Mitotic domains in the early embryo of the zebrafish. Nature 360:735-737.

Kato J, Matsuoka M, Polyak K, Massague J, Sherr CJ (1994) Cyclic AMP-induced $\mathrm{G} 1$ phase arrest mediated by an inhibitor ( $27^{\mathrm{Kipl}}$ ) of cyclin-dependent kinase 4 activation. Cell 79:487-496.

Kato J, Matsushime H, Hiebert SW, Ewen ME, Sherr CJ (1993) Direct binding of cyclin $\mathrm{D}$ to the retinoblastoma gene product $(\mathrm{pRb})$ and $\mathrm{pRb}$ phosphorylation by the cyclin-D dependent kinase CDK4. Genes Dev 7:331-342.

Kato J, Sherr C (1993) Inhibition of granulocyte differentiation by G1 cyclins D2 and D3 but not D1. Proc Natl Acad Sci USA 90:11513-11517.

Kaufman SL (1968) Lengthening of the generation cycle during cmbryonic differentiation of the mouse neural tube. Exp Cell Res 49:420-424.

Kimmel CB, Warga RM, Kane DA (1994) Cell cycle and clonal strings during formation of the zebrafish central nervous system. Development 120:265-276.

Lebwohl DE, Muise-Helmericks R, Sepp-Lorenzino L, Serve S, Timaul M, Bol R, Borgen P, Rosen N (1994) A truncated cyclin D1 gene encodes a stable mRNA in a human breast cancer cell line. Oncogene 9:1925-1929.

Mannick JB, Asano K, Izumi K, Kieff E, Stamler JS (1994) Nitric oxide produced by human B lymphocytes inhibits apoptosis and Epstein-Barr virus reactivation. Cell 79:1137-1146.

Marin-Padilla M (1971) Early prenatal ontogenesis of the cerebral cortex (neocortex) of the cat (Felis domestica). A Golgi study. I. The primordial neocortical organization. Z Anat Entwickl Gesch 134:117-145.

Marin-Padilla M (1988) Early ontogenesis of the human cerebral cortex. In: Cerebral cortex (Peters A, Jones EG, eds), pp 1-34. New York: Plenum.

Matsushime H, Ewen ME, Strom DK, Kato JY, Hanks SK, Roussel MF, Sherr CJ (1992) Identification and properties of an atypical catalytic subunit (p34PSK-J3/cdk4) for mammalian D type G1 cyclins. Cell 71:323-334

Matsushime H, Roussel MF, Ashmun RA, Sherr CJ (1991) Colonystimulating factor 1 regulates novel cyclins during the G1 phase of the cell cycle. Cell 65:701-713.

Matthias P, Hershowitz I (1994) Joining the complex: cyclin-dependent kinase inhibitory proteins and the cell cycle. Cell 79:181-184.

Miale I, Sidman R (1961) An autoradiographic analysis of histogenesis in the mouse cerebellum. Exp Neurol 4:227-296.

Murray A, Hunt T (1993) The cell cycle. New York: Freeman

Nasmyth K (1993) Control of the yeast cell cycle by the Cdc28 protein kinase. Curr Opin Cell Biol 5:166-179. 
Nurse $P$ (1994) Ordering $S$ phase and $M$ phase in the cell cycle. Cell 79:547-550.

Ohtsubo M, Roberts JM (1993) Cyclin-dependent regulation of G1 in mammalian fibroblasts. Science 259:1908-1912.

O'Leary D, Koester S (1993) Development of projection neuron types, axon pathways, and patterned connections of the mammalian cortex. Neuron 10:991-1006.

Pardee AB (1989) Gl events and regulation of cell proliferation. Science 246:603-608.

Peunova N, Enlkolopov G (1995) Nitric oxide triggers a switch to growth arrest during differentiation of neuronal cells. Nature 375:68-73.

Quelle DE, Ashmun RA, Shurtleff SA, Kato J-Y, Bar-Sagi D, Roussel MF, Sherr CI (1993) Overexpression of mouse D-type cyclins accelerates G1 phase in rodent fibroblasts. Genes Dev 7:1559-1571.

Rakic $P$ (1971) Neuron-glia relationship during granule cell migration in dcveloping ccrcbcllar cortex: a Golgi and clectron microscopic study in Macacus rhesus. J Comp Neurol 141:283-312.

Ramon y Cajal S (1911) Histologie du system nerveux de l'home et des vertebres. Paris: Maloine.

Reed SI, Dulic V, Lew DJ, Richardson HE, Wittenberg C (1992) G1 control in yeast and animal cells. Ciba Found Symp 170:7-15.

Roberts JM (1993) Turning DNA replication on and off. Curr Opin Cell Biol 5:201-206.

Ross M, Risken M (1994) MN20, a D2 cyclin found in brain, is implicated in neural differentiation. J Neurosci 14:6384-6391.

Rothe M, Pehl M, Taubert H, Jackle H (1992) Loss of gene function through rapid mitotic cycles in the Drosophila embryo. Nature $359: 156-159$.

Ryder E, Cepko C (1994) Migration patterns of clonally related granule cells and their progenitors in the developing chick cerebellum. Neuron 12:1011-1029.

Sauer FC (1935) The cellular structure of the neural tube. J Comp Neurol 63:13-23.
Sauer ME, Chittenden AC (1959) Deoxyribonucleic acid content of cell nuclei in the neural tube of the chick embryo: evidence for intermitotic migration of nuclei. Exp Cell Res 16:1-6.

Schambra U, Lauder J, Silver J (1992) Atlas of the prenatal mouse brain. San Diego: Academic.

Schaper A (1897) The earliest differentiation in the central nervous system of vertebrates. Science 5:430-431.

Seymour RM, Berry M (1975) Scanning and transmission electron microscope studies of interkinetic nuclear migration in the cerebral vesicles of the rat. J Comp Neurol 160:105-126.

Shermoen AW, O'Farrell PH (1991) Progression of the cell cycle through mitosis leads to abortion of nascent transcripts. Cell 67:303-310.

Sherr CI (1993) Mammalian G1 cyclins. Cell 73:1059-1065.

Sherr CJ (1994) G1 phase progression: cycling on cue. Cell 79:551-555.

Takahashi T, Nowakowski RS, Caviness JVS (1993) Cell cycle parameters and patterns of nuclear movement in the ncocortical proliferative zone of the fetal mouse. J Neurosci 13:820-833.

Thomas BJ, Gunning DA, Cho J, Zipursky SL. (1994) Cell cycle progression in the developing Drosophila eye: roughex encodes a novel protein required for the establishment of G1. Cell 77:1003-1014.

Waechter RV, Jaensch B (1972) Generation times of the matrix cells during embryonic brain development: an autoradiographic study in rats. Brain Res 46:235-250.

Weiss P (1955) Nervous system. In: Analysis of development (Willier BH, Weiss P, Hamburger V, eds), pp 346-401. Philadelphia: Saunders.

Wilson DB (1982) The cell cycle during closure of the neural folds in the C57BL mouse. Dev Brain Res 2:420-424.

Xiong Y, Hannon GJ, Zhang H, Casso D, Kobayashi R, Beach D (1993) $\mathrm{p} 21$ is a universal inhibitor of cyclin kinases. Nature 366:701-704.

Xiong Y, Zhang H, Beach D (1992) D-type cyclins associate with multiple protein kinases and the DNA replication and repair factor PCNA. Cell 71:504-514. 